\title{
Association between induced abortion and suicidal ideation among unmarried female migrant workers in three metropolitan cities in China: a cross-sectional study
}

\author{
Mengyun Luo ${ }^{1+}$, Xueqin Jiang ${ }^{1+}$, Ying Wang ${ }^{1}$, Zezhou Wang ${ }^{1}$, Qiuming Shen ${ }^{1}$, Rui $\mathrm{Li}^{2^{*}}$ and Yong Cai ${ }^{1^{*}}$
}

\begin{abstract}
Background: Despite reports of mental health issues, suicidality has not been closely examined among the migrant population. The association between induced abortion and suicidal ideation is unknown among unmarried female migrant workers of reproductive age in China. This study aims to examine induced abortion and suicidality among the Chinese migrant population.

Methods: We recruited 5115 unmarried female migrant workers during 2015 to 2016 from Shanghai, Beijing and Guangzhou, and collected demographic, psychosocial, reproductive and mental health information using structured questionnaires. We used logistic regression models to examine the association between lifetime induced abortion and suicidal ideation during the past year among the subjects.

Results: Overall, $8.2 \%$ of the subjects had suicidal ideation during the past year, and $15.5 \%$ of the subjects experienced induced abortion. Induced abortion was associated with nearly twice the odds of having past-year suicidal ideation (Odds ratio, $\mathrm{OR}=1.89 ; 95 \%$ confidence interval, $\mathrm{Cl}: 1.46,2.44)$ after adjusting for age, education, years in the working place, tobacco use, alcohol consumption, daily internet use, attitude towards premarital pregnancy, multiple induced abortion, self-esteem, loneliness, depression, and anxiety disorders. The association was stronger in those aged $>25(\mathrm{OR}=3.37,95 \% \mathrm{Cl}=2.16,5.28)$, with $>5$ years of stay in the working place $(\mathrm{OR}=2.98,95 \% \mathrm{Cl}=2.02,4.39)$, the non-anxiety group $(\mathrm{OR}=2.28,95 \% \mathrm{Cl}=1.74,3.00)$, and the non-depression group $(\mathrm{OR}=2.94,95 \% \mathrm{Cl}=2.08,4.15)$.

Conclusions: Induced abortion was associated with increased odds for suicidal ideation among the unmarried female migrant workers in urban cities in China. More attention should be paid to the mental health of the population.
\end{abstract}

Keywords: Induced abortion, Suicidal ideation, Female migrant workers, Mental health

\section{Background}

As one of the hallmarks for global development, migration is and will continue to be associated with health issues. Internationally, migration is a process during which a person moves from one cultural setting to another [1], while internal migration usually occurs within

\footnotetext{
*Correspondence: Rui_Li@urmc.rochester.edu; caiyong202028@163.com ${ }^{\dagger}$ Equal contributors

${ }^{2}$ Department of Public Health Sciences, University of Rochester School of Medicine and Dentistry, Rochester, NY 14642, USA

'School of Public Health, School of Medicine, Shanghai Jiao Tong University, Shanghai 200025, People's Republic of China
}

a nation, and in China is characterized by the overwhelming rural-to-urban migration. It was estimated that there were 73 million migrants living in the World Health Organization (WHO) European Region in the early 2016 [2]. In China, the number tripled, corresponding to 247 million internal migrants living in the places different from their household registration, and the number will further increase to over 2 billion by 2020 [3]. Unlike most permanent residents who can enjoy the benefit of local public services and welfare systems, migrants, classified as temporary residents,

(c) The Author(s). 2018 Open Access This article is distributed under the terms of the Creative Commons Attribution 4.0 International License (http://creativecommons.org/licenses/by/4.0/), which permits unrestricted use, distribution, and reproduction in any medium, provided you give appropriate credit to the original author(s) and the source, provide a link to the Creative Commons license, and indicate if changes were made. The Creative Commons Public Domain Dedication waiver (http://creativecommons.org/publicdomain/zero/1.0/) applies to the data made available in this article, unless otherwise stated. 
generally experience disparities in their living conditions, including the exclusion from access to some medical services and social benefits [4], and experienced stigma and discrimination [5].

Between January and May 2010, twelve young migrants working in Foxconn Technology Group in Guangzhou attempted suicide among whom 10 died [6, 7], arousing public attention to the poor mental health of the migrant workers in China. It was reported that younger age (1835 years) was a risk factor while male gender and being married were protective factors for depression and anxiety disorders in the general population [8-10], and therefore unmarried female migrant workers of reproductive age might be under higher risk for developing mental health problems including suicidal ideation, which is defined as any self-reported thoughts of engaging in suicide-related behavior [11]. Although not sharing exactly the same risk factors as suicide, suicidal ideation is an established risk factor for suicide [12] which is the second leading cause of death among 15-29 year olds globally [13], and different from Western countries where the suicide mortality is constantly higher in males, in China the gender difference in suicide rate is not salient despite a shift towards the Western trend over time, and more suicidal attempts occur among females especially in rural areas [14]. Several studies reported higher risk for suicidal thoughts and attempts among migrant workers $[15,16]$, while others suggested similar risks compared to urban dwellers [10]. In a study conducted among rural young Chinese, the prevalence of serious past-year suicidal ideation was $1.3 \%$ among the migrant group and $3.0 \%$ among the nonmigrant group [17]. Another one reported 9.2\% past-year suicidal ideation among women of reproductive age working in entertainment venues in the capital city of one eastern Chinese province [18]. However, there is still a dearth of data on unmarried female migrant workers in China.

Nowadays, females account for nearly half of the whole internal migrant group in China, and the number is steadily growing [19]. Most of them are unmarried women of reproductive age. Disparities between nonmigrants and migrants in reproductive and maternal health, as well as family planning services accessibility result in higher incidences of induced abortion, caesarean section, and pregnancy complications [20]. As was reported, in China, nearly 15\% of the unmarried female migrants had an unwanted pregnancy and $95 \%$ of them had an abortion [21, 22], among whom half had repeated abortions [23]. These self-reported data may be an underestimate since premarital sex is generally regarded as shameful in the sexually conservative Chinese culture. Fetal loss is a traumatic experience and studies have shown that abortion was correlated with increased risk for subsequent mental disorders [24-26], and suicidal behaviors [27, 28]. Although induced abortion-related suicidality among unmarried female migrant workers was rarely reported, the risk might increase as a result of physical impairment following abortion, and multiple psychosocial stresses which could be either innate in the population or related to induced abortion [29].

As there were few studies targeting the mental health of unmarried female migrant workers, our study aimed to understand the mental health of the population in big cities in China. We examined the association between lifetime induced abortion and suicidal ideation during the past year, and further explored whether the association, if any, varied between different subgroups. We hypothesize that (1) lifetime induced abortion was positively associated with past-year suicidal ideation; (2) the association between induced abortion and suicidal ideation differed by age group, hometown, education attainment, length of stay in the city, attitude towards premarital pregnancy, and the presence of depression and anxiety disorders.

\section{Methods \\ Design and study population}

The study was conducted in Shanghai, Beijing and Guangzhou, three of the largest metropolitan cities attracting a great number of migrants in China. Approximately 20 million migrants in China are currently residing in these three cities [30-32]. The eligible criteria for the study subjects were unmarried females aged over 18 years and working in the place different from their household registration as migrants. The exclusion criterion was the inability to read or answer questions (e.g., dementia, difficulties with the language).

Between June 2015 and March 2016, we recruited participants using the convenient sampling method. Assuming a prevalence of past-year suicidal ideation in rural-to-urban female migrant workers of $8 \%$ [18, 33, 34], using $\alpha$ of 0.05 , and a relative error for sampling of 0.1 , we calculated a required sample size of 5500 to allow for the non-response rate of $20 \%$. In the first stage, we selected two factories from each city where female migrants congregated with the assistance of the officials from the local centers for disease control and prevention (CDC). In the second stage, we selected individuals compatible with the inclusion criteria from each factory with the help of the factory managers.

We conducted the survey with self-administrated questionnaires. We trained human resources specialists of the factories and senior undergraduate medical students from each city as investigators prior to the investigation. Each interview lasted approximately $30 \mathrm{~min}$ in a private room of each factory. We compensated each participant with 30 RMB (\$4-5 USD) in cash after they completed the questionnaire. The Ethics Committee approved the survey. We obtained written 
informed consent from all the participants following a clarification of the objectives and the procedure of the study, as well as the potential risks and benefits of participation before enrolling the participants.

\section{Instruments and measures \\ Psychosocial variables}

Psychosocial information included behavioral variables, attitudes toward premarital pregnancy and multiple abortion, as well as self-esteem and perceived loneliness. Behavioral variables included tobacco use, alcohol assumption and daily internet use within the past month which were assessed by four-point Likert scales questions asking the frequency of these behaviors $(1=$ never, $4=$ everyday). We only considered subjects as nonsmokers or non-drinkers if their answer was 'never' to the corresponding questions while we considered subjects as daily internet users if their answer was 'every day'. We assessed the attitudes towards premarital pregnancy and multiple abortion with two questions: "Do you agree with premarital pregnancy" and "Do you agree with multiple induced abortion", with the answers ranging from 1 (strongly agree) to 5 (strongly disagree). We considered subjects holding negative attitude towards premarital pregnancy or multiple induced abortion if their corresponding answers were "disagree or strongly disagree", and other answers ("strongly agree, agree or doesn't matter") as having positive attitude. We measured self-esteem using the 10-item, Likert-type Rosenberg Self Esteem Scale [35, 36]. After reversing the negative items, we calculated the total score with a higher score indicating higher self-esteem (Cronbach's alpha $=0.772$; range $0-30$ ). We further categorized the subjects into high- and low-level self-esteem groups with the cutoff point of 15 [37]. We measured the inner feeling of loneliness and the experience of human relationships with the 8-item ULS-8 Scale [38], a simplified version of the 20-item UCLA Loneliness Scale [39, 40]. Each item ranged from 1 (never) to 4 (most of the time), with a higher summed score indicating a higher level of loneliness (Cronbach's alpha $=0.694$; range $8-32$ ). We defined the group with significant loneliness as those with a total score greater than 17 , which was the 75th percentile in our study.

\section{Mental disorder variables}

We measured depressive symptoms using the 20-item Likert-type Center for Epidemiologic Studies Depression Scale (CESD) [41, 42]. A higher summed score indicated higher depression severity (Cronbach's alpha $=0.865$; range $0-60$ ). According to the literature, we adopted 20 as the diagnosis value [43]. We measured anxiety with the 7-item Likert-scale Generalized Anxiety Disorder (GAD-7) [44, 45], with a higher summed score indicating more severe generalized anxiety (Cronbach's alpha $=0.866$; range $0-21$ ). We defined those with the total score greater than 10 to be the anxiety group [44].

\section{Reproductive health}

For the reproductive health of the subjects, we asked three questions (Have you had premarital sex? Have you had unplanned pregnancy? Have you had the experience of induced abortion?). Subjects gave the response with "yes $=1$ " or "no $=0$ " for each question.

\section{Suicidality}

We measured suicidal ideation, suicidal plan and suicidal attempt during the past year using the questions "Have you ever.. . thought about killing yourself?"; ".. . made plans to kill yourself? "; and ".. . failed to kill yourself?" within the past year with the response "yes $=1$ " and "no $=0$ " for each question. For this study, we focused on the association between induced abortion and suicidal ideation due to heterogeneity in the risk factors across the spectrum of suicidality.

\section{Statistical analysis}

The quality of data was ensured by the double entry process. Cases with any missing data were excluded from the analysis. We used Chi-Square test to examine the association between each potential covariate with both the experience of induced abortion and past-year suicidal ideation as binary variables. Then using logistic regression analyses, we regressed each subject's past-year suicidal ideation against induced abortion, after adjusting for covariates in a hierarchical manner. We included demographic covariates in model 1 , with extra inclusion of psychosocial covariates in model 2 , and added depression and anxiety disorders in model 3 . We selected the covariates based on either literature or Chi-square test result with $p$-value $<0.1$. We calculated the Nagelkerke / Cragg \& Uhler's pseudo R-squared as a comparison of model fit [46].

To further explore whether the association between induced abortion and past-year suicidal ideation differed among different groups, we performed subgroup analyses by age group, hometown, education attainment, length of stay in the city, attitude towards premarital pregnancy, the presence of clinically significant anxiety disorders and depression. Each time we added an interaction term to model 3 and reported the corresponding Odds ratio (OR) with $95 \%$ Confidence Interval (CI), as well as the $p$-value for overall interaction effect.

\section{Results}

A total of 5578 unmarried female migrant workers agreed to participate in the study, with 5332 (95.6\%) meeting the inclusion criteria and of them, 5115 (95.9\%) 
completed the survey. Characteristics of the subjects were summarized in Table 1 . The mean age was $23.3 \pm 2.8$ years (range $=18-35)$. Over 15\% experienced induced abortion and over $8 \%$ reported suicidal ideation during the past year.

The characteristics of the subjects with and without induced abortion, with and without past-year suicidal ideation were summarized in Table 2. Compared to those without induced abortion, those with the experience were more likely to be aged $>25$, have lower education level but higher income, come from urban areas, have shorter stay in the working place, more likely to smoke, drink alcohol and surf the internet every day during the past month, have more positive attitude towards premarital pregnancy and multiple induced abortion, more likely to have low self-esteem and suicidal ideation during the past year. Compared to those without suicidal ideation, suicide ideators were more likely to have lower education and shorter stay in the working place, less likely to smoke but more likely to drink alcohol and report daily internet use, have more positive attitude towards premarital pregnancy and multiple induced abortion, more likely to have low selfesteem and experience loneliness, anxiety and depression, and have past experience of induced abortion.

The association between induced abortion and suicidal ideation was summarized in Table 3. Induced abortion was associated with nearly twice the odds of having suicidal ideation across three models, with slight reduction in the effect size with extra adjustment of psychosocial covariates in model 2 , and nearly no change with further adjustment of depression and anxiety in model 3. In model 3, higher education, longer stay in the working place and past-month smoking were associated with decreased, while past-month alcohol drinking and daily internet use, lower self-esteem, loneliness, depression and induced abortion with increased odds of suicidal ideation. The Nagelkerke $R^{2}$ was $1.5 \%$ in the binary model for induced abortion, with the greatest increase (10.8\%) with the introduction of psychosocial covariates.

The results for our subgroup analyses were summarized in Table 4. The association between induced abortion and suicidal ideation were significant among those aged $>20$ with larger effect among those aged $>25$, those with a length of stay of $<1$ year or $>5$ years with larger effect in the latter, and in the non-anxiety group and non-depression group. We did not find different effect associations by hometown, education level or attitude towards premarital pregnancy.

\section{Discussion}

To our knowledge, this was the first study targeting specifically at the association between induced abortion and suicidal ideation among unmarried female migrant populations working in urban cities in China, who are an important workforce in the national urbanization process but have received insufficient attention with regards to their mental health. We found nearly twice the odds of past-year suicidal ideation associated with the experience of induced abortion, which was independent of demographic, psychosocial and mental disorder characteristics. The association was stronger among those aged over 25 , having stayed in the working place for over 5 years, and without depression or anxiety disorders.

The prevalence of past-year suicidal ideation in our subjects, $8.2 \%$, was higher than $6.5 \%$ among rural female populations aged 16-34 [33], the lifetime suicidal ideation of 3.9\% among the general population [47] and 5.8\% among the urban dwellers of similar age range in China [10]. It is much higher than the $2.8 \%$ lifetime suicidal ideation prevalence reported among male migrant workers in railway construction site in China [48]. Higher rate of suicide and suicide attempt have been reported among migrants in Europe despite large heterogeneity for different migrant groups [1, 49]. Nearly $30 \%$ of our study subjects experienced depression, higher than that reported in other studies of Chinese migrant workers $[17,50,51]$, and the prevalence of anxiety was similar to previous report [50].

The positive association between induced abortion and suicidal ideation was consistent with previous studies. The first cohort study using national registry data in Finland reported over 3 times increased risk of suicide following induced abortion compared with the general population, which corresponded to nearly 6 times the risk compared to birth givers [52], and the higher risk even persists until now since the initiation of the Current Care Guideline in Finland which highlights monitoring the mental disorders of women during the post-termination window [53]. Positive associations between suicidal ideation and induced abortion were reported in longitudinal studies [54, 55]. In China, only one study reported no effect of abortion on suicidal ideation but negative effect on suicide acceptability among females aged 15-34 in rural areas [56]. Our study adds to the evidence of induced abortion-suicidality association and highlights the mental health issues among unmarried female migrant workers.

In our hierarchical analyses, induced abortion was associated with increased odds for suicidal ideation in all of the models. It was reported that migrant population in China have slight advantage in mental well-being than the general population $[9,17]$ but they are characterized by lower level of medical service utilization especially mental health services [51]. With little knowledge of contraception, and further complicated by the one-child policy implemented since 1978, as well as the 
Table 1 Characteristics of the study subjects $(N=5115)$ (Continued)

\begin{tabular}{|c|c|c|}
\hline Variables & $n$ & $\%$ \\
\hline Yes & 982 & 19.2 \\
\hline \multicolumn{3}{|l|}{ Daily Internet use-past month } \\
\hline No & 4555 & 89.1 \\
\hline Yes & 560 & 10.9 \\
\hline \multicolumn{3}{|l|}{ Attitude toward premarital pregnancy } \\
\hline Positive & 1046 & 20.4 \\
\hline Negative & 4069 & 79.6 \\
\hline \multicolumn{3}{|c|}{ Attitude toward multiple induced abortion } \\
\hline Positive & 156 & 3.0 \\
\hline Negative & 4959 & 97.0 \\
\hline \multicolumn{3}{|l|}{ Rosenberg Self Esteem Scale } \\
\hline High self-esteem (score > =15) & 4514 & 88.3 \\
\hline Low self-esteem (score < 15) & 601 & 11.7 \\
\hline \multicolumn{3}{|l|}{ GAD-anxiety } \\
\hline Non-anxiety group (score < 10) & 4506 & 88.1 \\
\hline Anxiety group (score > =10) & 609 & 11.9 \\
\hline \multicolumn{3}{|l|}{ CESD-depression } \\
\hline Non-depression group (score < 20) & 3615 & 70.7 \\
\hline Depression group (score > =20) & 1500 & 29.3 \\
\hline \multicolumn{3}{|l|}{ Have had premarital sex } \\
\hline No & 2142 & 41.9 \\
\hline Yes & 2973 & 58.1 \\
\hline \multicolumn{3}{|l|}{ Have had unplanned pregnancy } \\
\hline No & 4296 & 84.0 \\
\hline Yes & 819 & 16.0 \\
\hline \multicolumn{3}{|l|}{ Have had induced abortion } \\
\hline No & 4323 & 84.5 \\
\hline Yes & 792 & 15.5 \\
\hline \multicolumn{3}{|l|}{ Have had suicidal ideation-past year } \\
\hline No & 4697 & 91.8 \\
\hline Yes & 418 & 8.2 \\
\hline \multicolumn{3}{|l|}{ Have had suicidal plan-past year } \\
\hline No & 5032 & 98.4 \\
\hline Yes & 83 & 1.6 \\
\hline \multicolumn{3}{|l|}{ Have had suicidal attempt-past year } \\
\hline No & 5064 & 99.0 \\
\hline Yes & 51 & 1.0 \\
\hline Variables & Mean & Std. \\
\hline Age & 23.27 & 2.78 \\
\hline Rosenberg Self Esteem Scale & 18.79 & 3.77 \\
\hline UCLS Loneliness Scale & 4.46 & 3.94 \\
\hline GAD-anxiety & 14.84 & 3.99 \\
\hline CESD-depression & 16.75 & 9.35 \\
\hline
\end{tabular}

Table 1 Characteristics of the study subjects $(N=5115)$

\begin{tabular}{|c|c|c|}
\hline Variables & $\mathrm{n}$ & $\%$ \\
\hline \multicolumn{3}{|l|}{ City } \\
\hline Shanghai & 2255 & 44.1 \\
\hline Beijing & 1638 & 32.0 \\
\hline Guangzhou & 1222 & 23.9 \\
\hline \multicolumn{3}{|l|}{ Age (years) } \\
\hline$<20$ & 496 & 9.7 \\
\hline $20-25$ & 3353 & 65.6 \\
\hline$>25$ & 1266 & 24.8 \\
\hline \multicolumn{3}{|l|}{ Highest education } \\
\hline Middle school or below & 1465 & 28.6 \\
\hline Senior high school & 3233 & 63.2 \\
\hline College degree or above & 417 & 8.2 \\
\hline \multicolumn{3}{|l|}{ Income (RMB-yuan) } \\
\hline$<3200$ & 1869 & 36.5 \\
\hline $3200-4800$ & 3099 & 60.6 \\
\hline$>4800$ & 147 & 2.9 \\
\hline \multicolumn{3}{|l|}{ Hometown } \\
\hline Urban & 1253 & 24.5 \\
\hline Rural & 3862 & 75.5 \\
\hline \multicolumn{3}{|l|}{ Years in the working place } \\
\hline$<1$ & 2237 & 43.7 \\
\hline $1-5$ & 611 & 12.0 \\
\hline$>5$ & 2267 & 44.3 \\
\hline \multicolumn{3}{|l|}{ Tobacco use-past month } \\
\hline No & 4846 & 94.7 \\
\hline Yes & 269 & 5.3 \\
\hline \multicolumn{3}{|l|}{ Alcohol use-past month } \\
\hline No & 4133 & 80.8 \\
\hline
\end{tabular}

differentiated maternal health care practiced in urban cities toward local dwellers and migrant females, unplanned pregnancies predominantly end up with induced abortion among unmarried migrant female workers. In our data, the majority (96.9\%) of those having unplanned pregnancy underwent induced abortion. Induced abortion might be a natural choice for them but the consequence of abortion might have more lasting and complex impact on their emotion and mental well-being. The current maternal care system in urban cities can only trace reported pregnancy with a complete records of medical examination during pregnancy, which is less capable of capturing induced abortion and managing the posttermination health issues of the unmarried female population experienced with induced abortion.

In the final model, induced abortion and other behavioral and psychosocial characteristics overtook depression with relation to suicidal ideation, and anxiety was 
Table 2 Characteristics of the subjects with/without induced abortion, and with/without past-year suicidal ideation $(N=5115)$

\begin{tabular}{|c|c|c|c|c|c|c|}
\hline Variables & $\begin{array}{l}\text { With induced } \\
\text { abortion }(n=792)\end{array}$ & $\begin{array}{l}\text { Without induced } \\
\text { abortion }(n=4323)\end{array}$ & $p$-value & $\begin{array}{l}\text { With suicidal } \\
\text { ideation }(n=418)\end{array}$ & $\begin{array}{l}\text { Without suicidal } \\
\text { ideation }(n=4697)\end{array}$ & $p$-value \\
\hline \multicolumn{7}{|l|}{ Demographic characteristics } \\
\hline \multicolumn{7}{|l|}{ Resident City } \\
\hline Shanghai & $344(43.4 \%)$ & $1911(44.2 \%)$ & 0.337 & $170(40.7 \%)$ & 2085 (44.4\%) & 0.292 \\
\hline Beijing & $243(30.7 \%)$ & 1395 (32.3\%) & & $138(33.0 \%)$ & $1500(31.9 \%)$ & \\
\hline Guangzhou & 205 (25.9\%) & 1017 (23.5\%) & & $110(26.3 \%)$ & $1112(23.7 \%)$ & \\
\hline \multicolumn{7}{|l|}{ Age (years\%) } \\
\hline$<20$ & $52(6.6 \%)$ & $444(10.3 \%)$ & 0.004 & $49(11.7 \%)$ & 447 (9.5\%) & 0.220 \\
\hline $20-25$ & $530(66.9 \%)$ & $2823(65.3 \%)$ & & $260(62.2 \%)$ & $3093(65.9 \%)$ & \\
\hline$>25$ & $210(26.5 \%)$ & $1056(24.4 \%)$ & & 109 (26.1\%) & $1157(24.6 \%)$ & \\
\hline \multicolumn{7}{|l|}{ Highest education } \\
\hline Middle school or below & $289(36.5 \%)$ & $1176(27.2 \%)$ & $<0.001$ & $155(37.1 \%)$ & $1310(27.9 \%)$ & $<0.001$ \\
\hline Senior high school & $451(56.9 \%)$ & $2782(64.4 \%)$ & & $230(55.0 \%)$ & $3003(63.9 \%)$ & \\
\hline College degree or above & $52(6.6 \%)$ & $365(8.4 \%)$ & & $33(7.9 \%)$ & $384(8.2 \%)$ & \\
\hline \multicolumn{7}{|l|}{ Income (RMB-yuan) } \\
\hline$<3200$ & $246(31.1 \%)$ & $1623(37.5 \%)$ & $<0.001$ & $168(40.2 \%)$ & $1701(36.2 \%)$ & 0.236 \\
\hline $3200-4800$ & $506(63.9 \%)$ & $2593(60.0 \%)$ & & $237(56.7 \%)$ & $2862(60.9 \%)$ & \\
\hline$>4800$ & $40(5.1 \%)$ & $107(2.5 \%)$ & & $13(3.1 \%)$ & $134(2.9 \%)$ & \\
\hline \multicolumn{7}{|l|}{ Hometown } \\
\hline Urban & $218(27.5 \%)$ & $1035(23.9 \%)$ & 0.031 & $91(21.8 \%)$ & $1162(24.7 \%)$ & 0.176 \\
\hline Rural & $574(72.5 \%)$ & $3288(76.1 \%)$ & & $327(78.2 \%)$ & $3535(75.3 \%)$ & \\
\hline \multicolumn{7}{|l|}{ Years in the working place } \\
\hline$<1$ & $359(45.3 \%)$ & $1878(43.4 \%)$ & 0.101 & 217 (51.9\%) & $2020(43.0 \%)$ & 0.001 \\
\hline $1-5$ & $107(13.5 \%)$ & $504(11.7 \%)$ & & $52(12.4 \%)$ & $559(11.9 \%)$ & \\
\hline$>5$ & $326(41.2 \%)$ & $1941(44.9 \%)$ & & $149(35.6 \%)$ & $2118(45.1 \%)$ & \\
\hline \multicolumn{7}{|l|}{ Psychosocial characteristics } \\
\hline \multicolumn{7}{|l|}{ Tobacco use-past month } \\
\hline No & $726(91.7 \%)$ & $4120(95.3 \%)$ & $<0.001$ & $403(96.4 \%)$ & $4443(94.6 \%)$ & 0.110 \\
\hline Yes & $66(8.3 \%)$ & $203(4.7 \%)$ & & $15(3.6 \%)$ & $254(5.4 \%)$ & \\
\hline \multicolumn{7}{|l|}{ Alcohol use-past month } \\
\hline No & 557 (70.3\%) & $3576(82.7 \%)$ & $<0.001$ & $306(73.2 \%)$ & $3827(81.5 \%)$ & $<0.001$ \\
\hline Yes & $235(29.7 \%)$ & $747(17.3 \%)$ & & $112(26.8 \%)$ & $870(18.5 \%)$ & \\
\hline \multicolumn{7}{|l|}{ Daily Internet use-past month } \\
\hline No & $696(87.9 \%)$ & $3859(89.3 \%)$ & 0.250 & $345(82.5 \%)$ & $4210(89.6 \%)$ & $<0.001$ \\
\hline Yes & $96(12.1 \%)$ & $464(10.7 \%)$ & & $73(17.5 \%)$ & 487 (10.4\%) & \\
\hline \multicolumn{7}{|c|}{ Attitude toward premarital pregnancy } \\
\hline Positive & $321(40.5 \%)$ & $725(16.8 \%)$ & $<0.001$ & $108(25.8 \%)$ & $938(20.0 \%)$ & 0.004 \\
\hline Negative & $471(59.5 \%)$ & $3598(83.2 \%)$ & & $310(74.2 \%)$ & $3759(80.0 \%)$ & \\
\hline \multicolumn{7}{|c|}{ Attitude toward multiple induced abortion } \\
\hline Positive & $47(5.9 \%)$ & $109(2.5 \%)$ & $<0.001$ & $23(5.5 \%)$ & $133(2.8 \%)$ & 0.002 \\
\hline Negative & $745(94.1 \%)$ & $4214(97.5 \%)$ & & $395(94.5 \%)$ & $4564(97.2 \%)$ & \\
\hline \multicolumn{7}{|l|}{ Rosenberg Self Esteem Scale } \\
\hline High self-esteem (score $>=15$ ) & $679(85.7 \%)$ & $3883(89.8 \%)$ & 0.017 & $310(74.2 \%)$ & $4204(89.5 \%)$ & $<0.001$ \\
\hline
\end{tabular}


Table 2 Characteristics of the subjects with/without induced abortion, and with/without past-year suicidal ideation $(N=5115)$ (Continued)

\begin{tabular}{|c|c|c|c|c|c|c|}
\hline Variables & $\begin{array}{l}\text { With induced } \\
\text { abortion }(n=792)\end{array}$ & $\begin{array}{l}\text { Without induced } \\
\text { abortion }(n=4323)\end{array}$ & $p$-value & $\begin{array}{l}\text { With suicidal } \\
\text { ideation }(n=418)\end{array}$ & $\begin{array}{l}\text { Without suicidal } \\
\text { ideation }(n=4697)\end{array}$ & $p$-value \\
\hline Low self-esteem (score < 15) & $113(14.3 \%)$ & $440(10.2 \%)$ & & $108(25.8 \%)$ & $493(10.5 \%)$ & \\
\hline \multicolumn{7}{|l|}{ UCLS Loneliness Scale } \\
\hline Low loneliness (score < =17\%) & $598(75.5 \%)$ & $3287(76.0 \%)$ & 0.748 & $196(46.9 \%)$ & $3689(78.5 \%)$ & $<0.001$ \\
\hline High loneliness (score > 17) & $194(24.5 \%)$ & $1036(24.0 \%)$ & & $222(53.1 \%)$ & $1008(21.5 \%)$ & \\
\hline \multicolumn{7}{|l|}{ Mental disorders } \\
\hline \multicolumn{7}{|l|}{ GAD-anxiety } \\
\hline Non-anxiety group (score < 10) & $701(88.5 \%)$ & 3805 (88.0\%) & 0.694 & $333(79.7 \%)$ & $4173(88.8 \%)$ & $<0.001$ \\
\hline Anxiety group (score > =10) & $91(11.5 \%)$ & $518(12.0 \%)$ & & $85(20.3 \%)$ & $524(11.2 \%)$ & \\
\hline \multicolumn{7}{|l|}{ CESD-depression } \\
\hline Non-depression group (score < 20) & $494(62.4 \%)$ & 2757 (63.8\%) & 0.451 & $177(42.3 \%)$ & $3074(65.4 \%)$ & $<0.001$ \\
\hline Depression group (score > =20) & $298(37.6 \%)$ & $1566(36.2 \%)$ & & $241(57.7 \%)$ & $1623(34.6 \%)$ & \\
\hline \multicolumn{7}{|l|}{ Induced abortion } \\
\hline No & - & - & - & $310(74.2 \%)$ & $4013(85.4 \%)$ & $<0.001$ \\
\hline Yes & - & - & & $108(25.8 \%)$ & $684(14.6 \%)$ & \\
\hline \multicolumn{7}{|l|}{ Suicidal ideation-past year } \\
\hline No & $684(86.4 \%)$ & 4013 (92.8\%) & $<0.001$ & - & - & - \\
\hline Yes & $108(13.6 \%)$ & $310(7.2 \%)$ & & - & - & \\
\hline
\end{tabular}

no longer a significant predictor. Also contrary to western studies [54, 55, 57], we did not find associations between induced abortion and either depression or anxiety, which suggested some distinct links between induced abortion and suicidality among our population. Based on some overlapping characteristics of the subjects with induced abortion and suicidal ideation shown in our binary analyses(i.e., lower education, shorter stay in the working place, more alcohol consumption and internet use, more tolerant attitude towards primatial sex and multiple abortion, more likely to have low selfesteem), we could portrait a group of subjects who were less behaviorally strict but not necessarily more depressed or disturbed by mental disorders, and had lower level of social support which might in turn drive them to seek sensational or other problem behaviors. The link between the suicidal ideation and induced abortion among this population may not be mediated by depression, but more likely, an indication of some personality and temperament. Social support may play an important role here since the decision to continue or to give up the birth might be directly related to the perceived social support [58], and interpersonal connectedness is one of the core aspects of suicidality [59,60]. Among common theories in the explanation between abortion and mental distress [55], stress coping may play an essential role here due to the loose link between abortion and depression and anxiety, but the high prevalence of risky behaviors which may signify mal-coping strategies.
Despite that only $5.3 \%$ of the subjects reported tobacco use during the past month, the significant negative association between smoking and suicidal ideation warrant further research. Potential underreport of tobacco use could bias the association, or maybe smoking was regarded as a means for relieving the pressure among our subjects, which reduced their risk for suicidal ideation. The large increase in the Nagelkerke $R^{2}(10.8 \%)$ in model 2 highlights the psychosocial determinants of suicidality. In general, risk prediction for suicide is unsatisfactory [61], and the $\mathrm{R}^{2}$ of $14.0 \%$ in our final model was acceptable.

There seem to be stronger association between induced abortion and suicidal ideation with older age. It may be due to stronger emotional loss caused by fetal loss as age grows, or a manifestation of the accumulation of psychosocial stress overtime. Meanwhile, although longer stay in the working place was protective for suicidal ideation, the stronger association between abortion and suicidal ideation among those with longer stay is suggestive of the strengthening of some personality or propensity overtime. The stronger association among those without anxiety or depression further corroborates our inference that induced abortion was associated with suicidality independent of mental disorders among this population. Interestingly, among the anxiety group, induced abortion was associated with reduced odds of suicidal ideation despite the lack of power in revealing significance. A possible explanation might be that the 
Table 3 Multiple logistic regression of past-year suicidal ideation associated with induced abortion $(N=5115)$

\begin{tabular}{|c|c|c|c|}
\hline \multirow[t]{2}{*}{ Variables } & \multicolumn{3}{|c|}{$\begin{array}{l}\text { Suicidal ideation-past year } \\
\text { OR }(95 \% \mathrm{Cl})\end{array}$} \\
\hline & Model 1 & Model 2 & Model 3 \\
\hline \multicolumn{4}{|l|}{ Demographic characteristics } \\
\hline \multicolumn{4}{|l|}{ Age (years) } \\
\hline$<20$ & 1 & 1 & 1 \\
\hline $20-25$ & $0.77(0.55-1.06)$ & $0.77(0.55-1.08)$ & $0.74(0.53-1.05)$ \\
\hline$>25$ & $0.93(0.65-1.34)$ & $0.96(0.66-1.41)$ & $0.96(0.65-1.41)$ \\
\hline \multicolumn{4}{|l|}{ Highest education } \\
\hline Middle school or below & 1 & 1 & 1 \\
\hline Senior high school & $0.66(0.54-0.83)^{* *}$ & $0.70(0.56-0.88)^{* *}$ & $0.70(0.56-0.88)^{* *}$ \\
\hline College degree or above & $0.73(0.49-1.08)$ & $0.78(0.51-1.19)$ & $0.79(0.52-1.21)$ \\
\hline \multicolumn{4}{|l|}{ Years in the working place } \\
\hline$<1$ & 1 & 1 & 1 \\
\hline $1-5$ & $0.82(0.60-1.13)$ & $0.87(0.62-1.21)$ & $0.85(0.61-1.19)$ \\
\hline$>5$ & $0.66(0.53-0.82)^{* *}$ & $0.60(0.47-0.75)^{* *}$ & $0.58(0.46-0.73)^{* *}$ \\
\hline \multicolumn{4}{|l|}{ Psychosocial characteristics } \\
\hline \multicolumn{4}{|l|}{ Tobacco use-past month } \\
\hline No & & 1 & 1 \\
\hline Yes & & $0.22(0.12-0.39)^{* *}$ & $0.21(0.12-0.38)^{* *}$ \\
\hline \multicolumn{4}{|l|}{ Alcohol use-past month } \\
\hline No & & 1 & 1 \\
\hline Yes & & $1.63(1.25-2.13)^{* *}$ & $1.64(1.25-2.14)^{* *}$ \\
\hline \multicolumn{4}{|l|}{ Daily Internet use-past month } \\
\hline No & & 1 & 1 \\
\hline Yes & & $1.64(1.21-2.22)^{* *}$ & $1.63(1.20-2.21)^{* *}$ \\
\hline \multicolumn{4}{|l|}{ Attitude toward premarital pregnancy } \\
\hline Positive & & 1 & 1 \\
\hline Negative & & $0.89(0.69-1.16)$ & $0.88(0.68-1.14)$ \\
\hline \multicolumn{4}{|c|}{ Attitude toward multiple induced abortion } \\
\hline Positive & & 1 & 1 \\
\hline Negative & & $0.71(0.43-1.18)$ & $0.75(0.45-1.24)$ \\
\hline \multicolumn{4}{|l|}{ Rosenberg Self Esteem Scale } \\
\hline High self-esteem (score $>=15$ ) & & 1 & 1 \\
\hline Low self-esteem (score < 15) & & $1.95(1.49-2.55)^{* *}$ & $1.85(1.39-2.45)^{* *}$ \\
\hline \multicolumn{4}{|l|}{ UCLS Loneliness Scale } \\
\hline Low loneliness (score < =17) & & 1 & 1 \\
\hline High loneliness (score > 17) & & $3.64(2.92-4.53)^{* *}$ & $3.17(2.49-4.04)^{* *}$ \\
\hline \multicolumn{4}{|l|}{ Mental disorders } \\
\hline \multicolumn{4}{|l|}{ GAD-anxiety } \\
\hline Non-anxiety (score < 10) & & & 1 \\
\hline Anxiety (score $>=10$ ) & & & $0.85(0.62-1.16)$ \\
\hline \multicolumn{4}{|l|}{ CESD-depression } \\
\hline Non-depression (score < 20) & & & 1 \\
\hline Depression (score > =20) & & & $1.50(1.16-1.93)^{* *}$ \\
\hline
\end{tabular}


Table 3 Multiple logistic regression of past-year suicidal ideation associated with induced abortion ( $N=5115)$ (Continued)

\begin{tabular}{|c|c|c|c|}
\hline \multirow[t]{2}{*}{ Variables } & \multicolumn{3}{|c|}{$\begin{array}{l}\text { Suicidal ideation-past year } \\
\text { OR }(95 \% \text { Cl) }\end{array}$} \\
\hline & Model 1 & Model 2 & Model 3 \\
\hline \multicolumn{4}{|l|}{ Induced abortion } \\
\hline No & 1 & 1 & 1 \\
\hline Yes & $1.97(1.56-2.50)^{* *}$ & $1.89(1.46-2.45)^{* *}$ & $1.89(1.46-2.44)^{* * *}$ \\
\hline Nagelkerke R Square & 0.028 & 0.136 & 0.140 \\
\hline
\end{tabular}

termination was a relief to those unprepared mother-tobes which reduced their psychological burdens.

Our results should be interpreted considering the following limitations. Above all, we cannot draw causal conclusions due to the cross-sectional design. However, suicidal ideation measured within the past year and induced abortion measured within lifetime partly reduced reversal causality. Second, the clustered convenient sampling method brings selection bias although it is the most common method used for recruiting migrant workers who are usually highly aggregated.
Third, we did not discriminate between single-time abortion and multiple induced abortions, which may have different associations with suicidal ideation. Fourth, we did not measure potential confounders such as interpersonal violence, childhood experience, working environment, physical diseases and the experience of health seeking behavior, and we may have underestimated depression prevalence without asking antidepressant use. Fifth, we compared suicidal ideation between women with induced abortion and those without such experience most of whom we assumed to be never pregnant,

Table 4 Subgroup analyses of past-year suicidal ideation associated with induced abortion $(N=5115)$

\begin{tabular}{|c|c|c|c|c|}
\hline Variables & $n$ & $O R^{a}$ & $95 \% \mathrm{Cl}$ & $p$-value for interaction \\
\hline \multicolumn{5}{|l|}{ Age (years) } \\
\hline$<20$ & $496(9.7 \%)$ & 0.75 & $0.27-2.11$ & \multirow[t]{3}{*}{0.005} \\
\hline $20-25$ & $3353(65.6 \%)$ & 1.58 & $1.14-2.19$ & \\
\hline$>25$ & $1266(24.8 \%)$ & 3.37 & $2.16-5.28$ & \\
\hline \multicolumn{5}{|l|}{ Hometown } \\
\hline Urban & $1253(24.5 \%)$ & 1.52 & $0.90-2.57$ & \multirow[t]{2}{*}{0.351} \\
\hline Rural & $3862(75.5 \%)$ & 2.01 & $1.51-2.69$ & \\
\hline \multicolumn{5}{|l|}{ Highest education } \\
\hline Middle school or below & 1465 (28.6\%) & 1.75 & $1.17-2.62$ & \multirow[t]{3}{*}{0.891} \\
\hline Senior high school & $3233(63.2 \%)$ & 1.98 & $1.40-2.79$ & \\
\hline College degree or above & $417(8.2 \%)$ & 2.03 & $0.80-5.18$ & \\
\hline \multicolumn{5}{|l|}{ Years in the working place } \\
\hline$<1$ & 2237 (43.7\%) & 1.54 & $1.06-2.25$ & \multirow[t]{3}{*}{0.008} \\
\hline $1-5$ & $611(12.0 \%)$ & 0.96 & $0.46-1.99$ & \\
\hline$>5$ & 2267 (44.3\%) & 2.98 & $2.02-4.39$ & \\
\hline \multicolumn{5}{|c|}{ Attitude toward premarital pregnancy } \\
\hline Positive & $1046(20.4 \%)$ & 1.50 & $0.97-2.31$ & \multirow[t]{2}{*}{0.195} \\
\hline Negative & 4069 (79.6\%) & 2.14 & $1.56-2.92$ & \\
\hline \multicolumn{5}{|l|}{ GAD-anxiety } \\
\hline Non-anxiety (score < 10) & $4506(88.1 \%)$ & 2.28 & $1.74-3.00$ & \multirow[t]{2}{*}{0.001} \\
\hline Anxiety (score > =10) & 609 (11.9\%) & 0.64 & $0.31-1.30$ & \\
\hline \multicolumn{5}{|l|}{ CESD-depression } \\
\hline Non-depression (score < 20) & 3615 (70.7\%) & 2.94 & $2.08-4.15$ & \multirow[t]{2}{*}{$<0.001$} \\
\hline Depression (score > =20) & $1500(29.3 \%)$ & 1.20 & $0.83-1.74$ & \\
\hline
\end{tabular}

${ }^{a}$ Adjusting for all the other covariates in model 3 
but not ideally two groups of pregnant women with one experiencing induced abortion and the other delivering the baby. Nevertheless, the large sample size, the investigation in the three biggest cities in China with a wide geographic coverage, the structured questionnaire used across the three sites and the inclusion of a wide spectrum of covariates in the survey constituted the major strengths of our study.

\section{Conclusions}

Lifetime induced abortion was associated with nearly twice the odds for suicidal ideation during the past year among unmarried female migrant workers in metropolitan cities in China. An improvement of mental health of the population requires policy change, medical system support, enhanced communication between the service seekers and health care providers, and importantly, the establishment of an enabling environment to strengthen social support and facilitate help seeking behaviors of those less advantaged population.

\section{Abbreviations}

CDC: Center for Disease Control and Prevention; CESD: Center for Epidemiologic Studies Depression Scale; Cl: Confidence interval; GAD: Generalized Anxiety Disorder; OR: Odds ratio; WHO: World Health Organization

\section{Acknowledgements}

We are grateful to the study participants for their contribution. We thank the factories for helping us organize the survey.

\section{Funding}

This work was supported by the grants from the National Natural Science Foundation of China (71273174), the National Natural Science Foundation of China (71673187) and the Shanghai Key Discipline Construction Project in Public Health (15GWZK1002).

\section{Availability of data and materials}

The datasets generated and analyzed during the current study are not publicly available due to the funding nature (National Natural Science Foundation of China) but are available from the corresponding author on reasonable request.

\section{Authors' contributions}

$\mathrm{RL}$ and $\mathrm{YC}$ conceived the study design. XQJ, YW, ZZW and QMS performed the data collection. MYL and $Y C$ analyzed the data with the suggestions from other authors. MYL, XQJ, RL and YC wrote the manuscript. YW, ZZW and QMS contributed a lot to the discussion and revision of the manuscript. $\mathrm{RL}$ and $\mathrm{YC}$ supervised the study. All authors read and approved the final manuscript.

\section{Ethics approval and consent to participate}

The proposal of the study was reviewed and approved by the Chinese National Nature Science Fund Committee. The study was also approved by the Ethics Committee of School of Public Health, Shanghai Jiao Tong University. We obtained written informed consent from all the participants following a clarification the objectives and the procedure of the study, as well as the potential risks and benefits of participation before enrolling the participants.

\section{Competing interests}

The authors declare that they have no competing interests.

\section{Publisher's Note}

Springer Nature remains neutral with regard to jurisdictional claims in published maps and institutional affiliations.

Received: 21 December 2017 Accepted: 1 May 2018

Published online: 15 May 2018

\section{References}

1. Lindert J, Schouler-Ocak M, Heinz A, Priebe S. Mental health, health care utilisation of migrants in Europe. Eur Psychiatry. 2008;23:14-20.

2. World Health Organization. Migrant health in the European. Region 2017. http://www.euro.who.int/en/health-topics/health-determinants/ migration-and-health/migrant-health-in-the-european-region. Accessed 22 Auguest 2017

3. National Health and Family Planning Commission of the PRC. Report on China's migrant population development. China: Polulation Publishing House; 2016.

4. Hesketh T, Ye XJ, Li L, Wang HM. Health status and access to health Care of Migrant Workers in China. Public Health Rep. 2008;123:189-97.

5. Mcguire J, Li X, Wang B. Social stigma and quality of life among rural-tourban migrants in China: a comparison with their rural counterparts. World Health Popul. 2009:11:30-41.

6. Lau JT, Cheng Y, Gu J, Zhou R, Yu C, Holroyd E, et al. Suicides in a megasize factory in China: poor mental health among young migrant workers in China. Occup Environ Med. 2012;69:526.

7. Ngai P, Chan J. Global capital, the state, and Chinese workers the Foxconn experience. Modern China. 2012;38:383-410.

8. Breslau J, Borges G, Tancredi D, Saito N, Kravitz R, Hinton L, et al. Migration from Mexico to the United States and subsequent risk for depressive and anxiety disorders: a cross-national study. Arch Gen Psychiatry. 2011;68:428-33.

9. Li J, Chang SS, Yip PSF, Li J, Jordan LP, Tang Y, et al. Mental wellbeing amongst younger and older migrant workers in comparison to their urban counterparts in Guangzhou city. China: a cross-sectional study BMC public health. 2014;14:1280.

10. Li L, Wang HM, Ye XJ, Jiang MM, Lou QY, Hesketh T. The mental health status of Chinese rural-urban migrant workers : comparison with permanent urban and rural dwellers. Soc Psychiatry Psychiatr Epidemiol. 2007:42:716-22.

11. O'Carroll PW, Berman AL, Maris RW, Moscicki EK, Tanney BL, Silverman MM, et al. Beyond the tower of babel: a nomenclature for suicidology. Suicide Life Threat Behav. 1996:26:237-52.

12. O'Connor RC. The integrated motivational-volitional model of suicidal behavior. Crisis. 2011:32:295-8.

13. World Health Organization. Suicide data. 2017. http://www.who.int/mental_ health/prevention/suicide/suicideprevent/en/. Accessed 22 Augest 2017.

14. Page A, Liu S, Gunnell D, Astell-Burt T, Feng X, Wang L, et al. Suicide by pesticide poisoning remains a priority for suicide prevention in China: analysis of national mortality trends 2006-2013. J Affect Disord. 2017;208:418-23.

15. Carta MG, Bernal M, Hardoy MC, Haro-Abad JM. Migration and mental health in Europe (the state of the mental health in Europe working group: appendix 1). Clin Pract Epidemiol Ment Health. 2005:1:13.

16. Kwan YK, Ip WC. Suicidality and migration among adolescents in Hong Kong. Death Stud. 2007:31:45-66.

17. Dai J, Zhong BL, Xiang YT, Chiu HFK, Chan SSM, Yu X, et al. Internal migration, mental health, and suicidal behaviors in young rural Chinese. Soc Psychiatry Psychiatr Epidemiol. 2015;50:621-31.

18. Dong $Y$, Zhang $H$, Wang $Y, T$ Tan $H, X u S$, Xia J, et al. Multiple abortions and sexually transmitted infections among young migrant women working in entertainment venues in China. Women Health. 2015:55:580-94.

19. Information Office of the State Council. Annual report on gender equality and Women's development in China 2008-2012. China: Social Sciences Academic Press; 2013.

20. Keygnaert I, Ivanova O, Guieu A, Van Parys AS, Leye E, Roelens K. What is the evidence on the reduction of inequalities in accessibility and quality of maternal health care delivery for migrants? A review of the existing evidence in the WHO European region. 2016.

21. He D, Zhou Y, Ji N, Wu S, Wang Z, Decat P, et al. Study on sexual and reproductive health behaviors of unmarried female migrants in China. J Obstet Gynaecol Res. 2012;38:632-8. 
22. Qian X, Tang S, Garner P. Unintended pregnancy and induced abortion among unmarried women in China: a systematic review. BMC Health Serv Res. 2004:4:1.

23. Zeng J, Zou G, Song X, Li L. Contraceptive practices and induced abortions status among internal migrant women in Guangzhou, China: a crosssectional study. BMC Public Health. 2015;15:552.

24. Bellieni CV, Buonocore G. Abortion and subsequent mental health: review of the literature. Psychiatry Clin Neurosci. 2013;67:301-10.

25. Broen AN, Moum T, Bodtker AS, Ekeberg O. The course of mental health after miscarriage and induced abortion: a longitudinal, five-year follow-up study. BMC Med. 2005;3:18.

26. Steinberg JR, Trussell J, Hall K, Guthrie K. Fatal flaws in a recent metaanalysis on abortion and mental health. Contraception. 2012;86:430-7.

27. Fergusson DM, Horwood LJ, Ridder EM. Abortion in young women and subsequent mental health. J Child Psychol Psychiatry. 2006;47:16-24.

28. Mota NP, Burnett M, Sareen J. Associations between abortion, mental disorders, and suicidal behaviour in a nationally representative sample. Can J Psychiatr. 2010;55:239-47.

29. Fellmeth G, Paw MK, Wiladphaingern J, Charunwatthana P, Nosten FH, Mcgready R. Maternal suicide risk among refugees and migrants. Int J Gynaecol Obstet. 2016;134:223-4.

30. Gao XL, McGrath C, Lin HC. Oral health status of rural-urban migrant children in South China. Int J Paediatr Dent. 2011;21:58-67.

31. National Baureau of Statistics of the People's Republic of China. The sixth census data bulletin of shanghai in 2010. 2011. http://www.stats.gov.cn/tjjj/tjgb/rkpcgb/ dfrkpcgb/201202/t20120228_30403.html. Accessed 22 Augest 2017.

32. Xu T, Gong L, Wang H, Zhang R, Wang X, Kaime-Atterhog W. Epidemiology of unintentional injuries among children under six years old in floating and residential population in four communities in Beijing: a comparative study. Matern Child Health J. 2014;18:911-9.

33. Dai J, Chiu HF, Conner KR, Chan SS, Hou ZJ, Yu X, et al. Suicidal ideation and attempts among rural Chinese aged $16-34$ years-socio-demographic correlates in the context of a transforming China. J Affect Disord. 2011;130:438-46.

34. Yan Z, Peng A, Zhang L. Study on psychosocial factors of suicide ideation among peasant workers in Guiyang City. Journal of Hygiene Research. 2009:38:571-3.

35. Rosenberg M. Society and the adolescent self-image. Princeton: Princeton University Press; 1965.

36. Martin CR, Thompson DR, Chan DS. An examination of the psychometric properties of the Rosenberg self-esteem scale (RSES) in Chinese acute coronary syndrome (ACS) patients. Psychol Health Med. 2006;11:507-21.

37. Polat B, Orhan KS, Kesimli MC, Gorgulu Y, Ulusan M, Deger K. The effects of indwelling voice prosthesis on the quality of life, depressive symptoms, and self-esteem in patients with total laryngectomy. Eur Arch Otorhinolaryngol. 2015;272:3431-7.

38. Hays RD, MR DM. A short-form measure of loneliness. J Pers Assess. 1987;51:69-81.

39. Russell D, Peplau LA, Cutrona CE. The revised UCLA loneliness scale: concurrent and discriminant validity evidence. J Pers Soc Psychol. 1980;39:472-80.

40. Wu CH, Yao G. Psychometric analysis of the short-form UCLA loneliness scale(ULS8) in Taiwanese undergraduate students. Pers Individ Dif. 2008;44:1762-71.

41. Radloff LS. The CES-D scale: a self-report depression scale for research in the general population. Appl Psychological Meas. 1977;1:385-401.

42. Chin WY, Choi EP, Chan KT, Wong CK. The psychometric properties of the Center for Epidemiologic Studies Depression Scale in Chinese primary care patients: factor structure, construct validity, reliability, Sensitivity and Responsiveness. PLoS One. 2015;10:e0135131.

43. Gemma V, Forero CG, Gabriela B, Jordi A. Screening for depression in the general population with the Center for Epidemiologic Studies Depression (CES-D): a systematic review with meta-analysis. PLoS One. 2016;11:e0155431.

44. Spitzer RL, Kroenke K, Williams JB, Lowe B. A brief measure for assessing generalized anxiety disorder: the GAD-7. Arch Intern Med. 2006;166:1092-7.

45. He XY, Li CB, Jie Q, Cui H, Wu WY. Reliability and validity of a generalized anxiety disorder scale in general hospital outpatient. Shanghai Arch Psychiatry. 2010;22:200-3.

46. UCLA, Institute for Digital Research and Education. FAQ: what are pseudo rSQUAREDS? 2011. https://stats.idre.ucla.edu/other/mult-pkg/faq/general/faqwhat-are-pseudo-r-squareds/. Accessed 22 Augest 2017.

47. Cao X, Zhong B, Xiang Y, Ungvari GS, Lai KYC, Chiu HFK, et al. Prevalence of suicidal ideation and suicide attempts in the general population of China: a meta-analysis. Int J Psychiatry Med. 2015;49:296-308.
48. Sun YH, Zhou JB, Wang B. Survey of suicidal ideation and suicide attempts in the migrant workers in railway construction. Chinese Prevention Medicine. 2008;9:334-8.

49. Garssen MJ, Hoogenboezem J, Kerkhof AJ. Suicide among migrant populations and native Dutch in the Netherlands. Ned Tijdschr Geneeskd. 2006;150:2143-9.

50. Wang Z, Wang $L$, Jing J, Hu C. Prevalence of mental disorders in migrants compared with original residents and local residents in Ningxia. China BMC psychiatry. 2016;16:366.

51. Wei Z, Hu C, Wei X, Yang H, Shu M, Liu T. Service utilization for mental problems in a metropolitan migrant population in China. Psychiatr Serv. 2013;64:645-52.

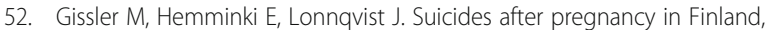
1987-94: register linkage study. BMJ (Clinical research ed). 1996;313:1431-4.

53. Gissler M, Karalis E, Ulander VM. Decreased suicide rate after induced abortion, after the current care guidelines in Finland 1987-2012. Scandinavian journal of public health. 2015;43:99-101.

54. Fergusson DM, Horwood LJ, Boden JM. Abortion and mental health disorders: evidence from a 30-year longitudinal study. Br J Psychiatry. 2008; 193:444-51.

55. Sullins DP. Abortion, substance abuse and mental health in early adulthood: thirteen-year longitudinal evidence from the United States. SAGE Open Med. 2016;4:1-11.

56. Zhang J, Sun L. Suicide ideation and acceptability among females aged 15 to 34 years in rural China. J Nerv Ment Dis. 2014;202:161-6.

57. Pedersen W. Abortion and depression: a population-based longitudinal study of young women. Scandinavian journal of public health. 2008;36:424-8.

58. Mantovani $\mathrm{N}$, Thomas $\mathrm{H}$. Choosing motherhood: the complexities of pregnancy decision-making among young black women 'looked after' by the state. Midwifery. 2014;30:72-8.

59. Joiner T. Why people die by suicide. Cambridge: Harvard University Press; 2005

60. Orden KAV, Witte TK, Cukrowicz KC, Braithwaite S, Selby EA, Jr TEJ. The interpersonal theory of suicide. Psychol Rev. 2010;117:575-600.

61. Large M, Kaneson M, Myles N, Myles H, Gunaratne P, Ryan C. Meta-analysis of longitudinal cohort studies of suicide risk assessment among psychiatric patients: heterogeneity in results and lack of improvement over time. PLoS One. 2016:11:e0156322.

\section{Ready to submit your research? Choose BMC and benefit from:}

- fast, convenient online submission

- thorough peer review by experienced researchers in your field

- rapid publication on acceptance

- support for research data, including large and complex data types

- gold Open Access which fosters wider collaboration and increased citations

- maximum visibility for your research: over $100 \mathrm{M}$ website views per year

At BMC, research is always in progress.

Learn more biomedcentral.com/submissions 